\title{
Antecedents and consequences of knowledge management performance: The role of IT infrastructure
}

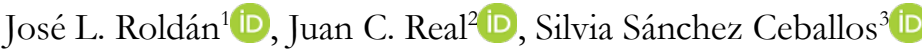 \\ ${ }^{1}$ Universidad de Sevilla (Spain) \\ ${ }^{2}$ Universidad Pablo de Olavide (Spain) \\ ${ }^{3}$ IAT (Instituto Andaluz de Tecnologia) (Spain) \\ jlroldan@us.es,jcreafer@upo.es,silviasanchezceballos@gmail.com
}

Received June, 2017

Accepted June, 2018

\begin{abstract}
Purpose: In this paper, we assess the role of knowledge management (KM) practices as a key antecedent of KM performance. Also, we examine how information technology (IT) infrastructure is used as a driver of KM performance, organizational performance and innovation. In addition, the effects of IT infrastructure can be indirect. Specifically, we show that KM performance is a mediator between, on the one hand, IT infrastructure and, on the other hand, organizational performance and innovation.
\end{abstract}

Design/methodology: Applying Partial Least Squares (PLS), a composite-based structural equation modeling, we have carried out a study among a sample of 82 Andalusian technology-intensive innovative companies adopting both a confirmatory and predictive purposes.

Findings: First, both IT infrastructure and KM practices are key drivers of KM performance. Second, KM performance shows a significant direct impact on business performance and innovation outcomes. Third, the influence of IT infrastructure on business performance and innovation outcomes is not direct but indirect through KM performance. Finally, the model shows good fit values and appropriate predictive power to predict new observations of KM performance and organizational performance.

Practical implications: This research provides insights for why some firms may not be realizing benefits from investing in IT infrastructure. KM performance is strongly needed for the successful implementation of IT infrastructure in the organizations.

Originality/value: This study has a double research purpose, confirmatory and predictive. In this vein, it applies new PLS developments focused on the goodness of fit as well as on the predictive performance of the model. The findings are important for practitioners and researchers because this study makes a contribution to the literature on KM by supporting the perspective that the business and organizational performance are functions of the KM performance, a complementary resource through which the value of IT infrastructure is enhanced.

Keywords: Knowledge management performance, IT infrastructure, Innovation, Knowledge management practices, Organizational performance, Partial Least Squares (PLS), Predictive performance

Jel Codes: D83, O31 


\section{To cite this article:}

Roldán, J.L., Real, J.C., \& Sánchez Ceballos, S. (2018). Antecedents and consequences of knowledge management performance: The role of IT infrastructure. Intangible Capital, 14(4), 518-535. https://doi.org/10.3926/ic.1074

\section{Introduction}

Knowledge management $(\mathrm{KM})$ is an interdisciplinary field in which contributions from different fields converge. Thus, the initiatives that can be undertaken to manage knowledge are also the most heterogeneous (Holsapple \& Joshi, 2003). There are many definitions of KM (Argote, Mc Evily \& Reagans, 2003). This research considers $\mathrm{KM}$ as the set of mechanisms that an organization articulates to promote the generation and use of knowledge. Thus, firms that are able to effectively manage knowledge resources are hoping to obtain benefits such as improved customer service, reduced infrastructure costs, improved decision making, innovation, promoting organizational agility and speed in developing new product lines, among others (Alavi, Kayworth \& Leidner, 2005).

An adequate level of performance in a $\mathrm{KM}$ program requires processes that encourage and share that knowledge. The KM practices are managerial or organizational initiatives with a strong operational character to achieve organizational goals, through efficient and effective management of the firm's knowledge resources (Inkinen, 2016). These actions may be focused on the maintenance and protection of knowledge (Keying, Rui \& Xiaoli, 2010), the outside capture (Alavi et al., 2005), codifying (Hansen, Nohria \& Tierney, 1999) or the human factor (Razmerita, Kirchner \& Sudzina, 2009).

The relationship between the KM performance and the business performance has been highlighted by authors such as Davenport (1999). Swan, Newell, Scarbrough and Hislop (1999), argue that KM actions contribute to the development of innovation. However, the relationship between $\mathrm{KM}$ and performance is an interesting question yet to be resolved (Inkpen \& Crossan, 1995). Wu, Dou and Fan (2009) also reveal possible differences in terms of exploration and exploitation of knowledge and firm performance. Organizational performance can be evaluated, and performance measurement can help companies examine strategies over time and help shape the strategic direction of the firm (Venkatraman \& Ramanujam, 1986). However, the contribution of the performance of KM initiatives is an interesting question yet to be resolved.

Information technology (IT) is also used to facilitate efforts in KM (O'Leary, 2003). In addition, KM in organizations should help optimize their information resources, as well as knowledge of the persons composing it and contribute to improving their efficiency and innovation capability. The finding that technical IT infrastructure played a very weak role in results agrees with a study based on the resource-based view (RBV). Powell and Dent-Micallef (1997) stated that IT, as an isolated asset, could not be regarded as a strategic resource. However, when IT is coordinated with complementary organizational resources, it becomes a source of competitive advantage. In this vein, there are several studies that do not find a significant positive relationship between IT infrastructure and overall performance (Loveman, 1994). This situation gives rise to the emergence of the technological productivity paradox (Lucas, 1999), according to which the IT infrastructure is not automatically transformed into improved outcomes for the companies.

Taking the previous puzzle into account, the following research questions arise: Are KM practices and the IT infrastructure key antecedents of KM performance? What are the impacts of KM performance on organizational and innovation outcomes? Does the IT infrastructure have a direct impact on organizational performance and innovation outcomes?

With the aim of finding an answer, we have carried out a study using a sample $(\mathrm{n}=82)$ of innovative companies in Andalusia (Spain). The research model was evaluated by applying the Partial Least Squares (PLS) technique adopting, (1) a confirmatory purpose in order to understand the causal relationships between constructs (Henseler, 2018), and, (2) a predictive aim that allows it to be determined whether the model is able to make predictions for individual cases (Shmueli, Ray, Velasquez Estrada \& Chatla, 2016). 
The structure of this paper is as follows. After this introduction, we propose the theoretical background and the hypotheses. Then, we describe the methodological aspects of this research and the results. Finally, we present the discussion, the theoretical and practical implications, and the limitations and future lines of research.

\section{Theory and hypotheses}

\subsection{KM practices and $\mathrm{KM}$ performance}

KM practices are KM initiatives and activities with a distinct operational nature, such as working methods and procedures. KM practices are defined as conscious and intentional organizational decisions projected to achieve organizational goals through efficient and effective management of the firm's knowledge resources (Inkinen, 2016).We refer to specific activities that allow and foster the sharing, maintenance and protection of knowledge. The aim is to strengthen the knowledge cycle. Within the literature there are no constant dimensions identified to measure KM practices (Altarawneh \& Altarawneh, 2017). For the purpose of this study, these practices can be classified into four dimensions according to their purposes: knowledge maintenance and protection, external knowledge capturing, knowledge codification, and practices focused on the human factor. Davenport and Prusak (1998) argue that an appropriate use of knowledge together with new knowledge creation can improve organizational productivity and also inspire creativity.

$\mathrm{KM}$ performance reflects the outcomes that come from the implementation of $\mathrm{KM}$ practices and technologies. In this line, a coherent development of KM actions can produce a greater impact on the results (Donate \& Guadamillas, 2007). Grant (1996) points out that the application and generation of knowledge cannot be considered in isolation. So, an integrated implementation of these KM practices would positively promote the outcomes. With regard to KM practices, Handzic (2015) notes that social initiatives may be more important than techniques for a successful KM implementation. Based on the above comments, the following hypothesis is stated:

\section{H1: KM practices are positively associated with KM performance}

\subsection{KM performance and organizational performance}

Organizational performance can be defined as the degree to which the company achieves its business objectives (Elenkov, 2002). The ability of an organization to acquire, share, use and create knowledge can positively influence financial outcomes (Garvin, 1993). According to Chong, Salleh, Ahmad and Sharifuddin (2011), there are positive effects of knowledge sharing processes on organizational performance. The processes of knowledge sharing and technology resources are important antecedent variables of organizational outcomes (Alavi \& Leidner, 2001). Thus, Ho (2009) concludes that KM should have a positive impact on organizational performance. Taking these considerations into account, the following hypothesis is stated:

\section{H2: KM performance is positively associated with organizational performance}

\subsection{KM performance and innovation}

The Oslo Manual (OECD, 2005) makes a clear reference to the relationship between innovation and KM. In this paper, we consider innovation as goods or services that are new or significantly improved, and/or new or significantly improved processes (OECD, 2005). Innovations emerge from the intersection of people and knowledge flows (Starbuck, 1992). KM is usually presented as a means to the innovation process (Scarbrough, 2003).

KM and its impact on the innovative capability have been studied by different researchers from the nineties (Daghfous \& White, 1994; Leonard-Barton, 1995; Kerssens-van Drongelen, Weerd-Nederhof \& Fisscher, 1996; Stanovcic, Pekovic \& Bouziri, 2015). A company managing knowledge uses resources more efficiently, and will therefore be more innovative and achieve a better performance (Darroch, 2005). Wang and Wang (2012) develop a research model which postulates that knowledge sharing affects innovation. Based on the above arguments, the following hypothesis is proposed:

\section{H3: KM performance is positively associated with innovation}




\subsection{IT infrastructure and $\mathrm{KM}$ performance}

The literature regarding the effects of IT resources recognizes one research stream from the technical perspective where the knowledge management processes are supported by infrastructure, techniques, and systems (Mao, Liu, Zhang \& Deng, 2016). According to this perspective, IT infrastructure refers to technology resources to support knowledge flows in an organization (Gold, Malhotra \& Segards, 2001). IT infrastructure includes both the hardware and software applications that underlie the knowledge use (Real, Roldán \& Leal, 2006).

In recent years, several researchers have associated knowledge processes with the development of IT (King, 2005; Choi, Lee \& Yoo, 2010). IT tools can facilitate communications and support for collaborative works, regardless of time and place, and it is an indispensable part of KM practices (Chadha \& Saini, 2014). IT infrastructure is a key antecedent of successful KM initiatives (Serenko, Bontis \& Hull, 2016). IT can enable access and retrieval of information and can support collaboration and communication between organizational members (Ho, 2009). In essence, IT infrastructure can play a variety of roles to support the organization's KM processes.

It is undisputed that IT is a key factor for KM implementation (Migdadi, 2009). According to Turban, Aronson, Liang, Sharda, Delen \& King (2010), there are several IT categories that serve as a basis for KM: communication, collaboration, storage and recovery technologies. In addition, those decision-making tools included under the business intelligence umbrella can be added. Moreover, IT is related to the different KM processes, including knowledge creation (Pawlosky, Forslin \& Reinhardt, 2001). In this way, there are a variety of methods, tools and actions that may support the process of knowledge generation and creation (Nonaka, Toyama \& Byosiere, 2001). Riege (2005) highlights that the key issue is to choose and implement an appropriate information technology infrastructure which provides a perfect fit between people and organizations. In this regard, Haque and Anwar (2012) found that technical infrastructure makes the employees technically capable to create, transmit and apply knowledge; it acts as a medium for the flow of knowledge. From these considerations, we postulate that:

\section{H4: IT infrastructure is positively associated with KM performance}

\subsection{IT and organizational performance}

The strategic importance of IT as a source of competitive advantages is underlined from various perspectives. From an industrial approach, based on the structure-conduct-performanceparadigm, IT use can provide a competitive advantage for firms (Kettinger, Grover, Guha \& Segars, 1994). Davenport and Prusak (1998) highlight the importance of technological advances in $\mathrm{KM}$ effectiveness and its overall contribution in organizational performance. Similarly, there are many studies that have shown a positive relationship between IT investment and performance (Mahmood \& Mann, 1993; Kelly, 1994; Brynjolfsson \& Hitt, 1996). Luftman, Lyytinen and Zvi (2017) consider that IT infrastructure is an element that needs to be aligned with other activities for its positive impact on business performance. Mills and Smith (2011) also refer to most researchers observing a positive relationship between technological infrastructures and company performance. Grant (1991) believes that IT can be considered as a key requirement to customer value creation, enabling the firm to beat the competition. These arguments lead us to state the following hypothesis:

\section{H5: IT infrastructure is positively associated with organizational performance}

\subsection{IT infrastructure and innovation}

Rampersad, Plewa and Troshani (2012) note a paucity of research about the use of IT for innovation management. The existing studies have examined IT as a medium of operations and an exogenous factor that affects innovation, but these studies have not found a clear link between IT and innovation (Asaad \& Marane, 2016). Tushman (1977) documented the importance of information from multiple sources, both inside and outside the organization, for innovation processes. Dewett and Jones (2001) suggested that IT infrastructure facilitates innovation by the principle of information efficiency. Recent studies (Durmusoglu \& Barczak, 2011; Kleis Chwelos, Ramirez \& Cockburn, 2012) have focused on understanding how and when IT tools and applications increase the probability of successful innovations. Real et al. (2006) indicate that IT infrastructure is a driver of the development of distinctive technological competencies, i.e., the ability to develop and design new 
products, services and processes. Also, Cooper (2003) presents a practical experience of the influence of IT on the development of new products. According to the above arguments, we formulate the following hypothesis:

\section{H6: IT infrastructure is positively associated with innovation}

Figure 1 summarizes the research model and hypotheses.

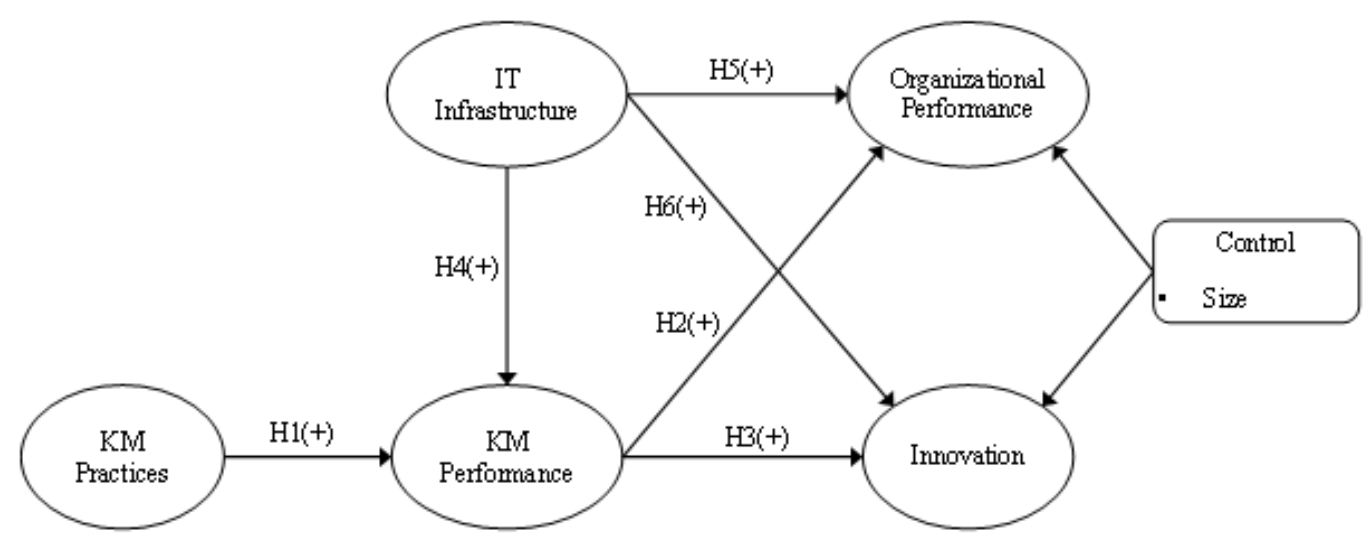

Figure 1. Research model

\section{Method}

\subsection{Participants}

The population of this study is made up of Andalusian innovative firms that have implemented knowledge management practices. Given the inherent problem of identifying its specific components, we follow a snowball sampling (Biernacki \& Waldorf, 1981) procedure to obtain a convenient final sample of 82 companies, based on the contributions of several consulting firms. The organizations participating in this study belonged primarily to the knowledge intensive services (50\%), services $(28 \%)$ and manufacturing sectors (22\%). According to the European Union classification, most of the participating entities are small and medium enterprises (73.2\%). All companies have set in motion knowledge management initiatives, although only $51.4 \%$ of them have a formal program of knowledge management being implemented.

Respondents of the survey were managers with a direct knowledge of their organizations' KM activities. Of the participants, $24.4 \%$ belonged to the quality department, followed by members of the senior management (20.4\%), operations $(13.4 \%)$, and human resources department $(13.4 \%)$.

\subsection{Measures}

All the constructs included in this study can be considered as design constructs or artifacts, that is to say, humanmade instruments theoretically justified and typically created by managers and staff in companies (Henseler, 2017a), such as management instruments, innovations, or information systems (Henseler, Hubona \& Ray, 2016). Since such artifacts are shaped from a series of elementary parts or components which are combined to form a new entity, Henseler (2017a) suggests modeling them as composites. In this vein, a composite measurement model represents constructs as weighted linear combinations of its indicators (Nitzl \& Chin, 2017), where indicators neither cause nor reflect the construct, but compose it (Henseler, 2017a).

Whenever possible, items were derived and translated from previously verified sources (Appendix). In this respect, KM performance and business performance variables were measured by scales adapted from the study of Venkatraman and Ramanujam (1986). We used five items (5-point Likert scale) for both variables. On the other hand, for the rest of the cases, the items used to measure the variables of interest were created specifically for this study. Thus, KM practices were measured by four indicators that count implemented practices in four dimensions (CWA 2004; Earl 2003, 2005; OECD, 2005): knowledge maintenance and protection, external knowledge capturing, knowledge codification, and knowledge generating and sharing practices based on the human factor. The IT infrastructure for the KM construct was measured by three items that consider IT 
applications implemented in three areas (Alavi \& Leidner, 2001; Turban et al. 2010; Xu \& Quaddus, 2005): communication and collaboration, information storage and recovery, and business intelligence applications. The innovation variable was measured by one item with four levels (Earl, 2005), from 1 (no innovation in processes and products) to 4 (innovation in processes and products). Finally, we included a control variable, Size. This was measured by one item: number of employees.

\subsection{Data analysis}

In order to test our hypotheses, we have used the Partial Least Squares (PLS) technique, a composite-based structural equation modeling (Rigdon, 2013). We have chosen PLS taking the following reasons into account: (1) given we aim to estimate a model of composites, then we should use a composite-based method like PLS (Rigdon, Sarstedt \& Ringle, 2017; Sarstedt, Hair, Ringle, Thiele \& Gudergan, 2016); (2) this research has a double purpose, explanation and prediction of the dependent variables (Henseler, 2018; Shmueli et al., 2016); (3) the research model is complex in terms of its number of indicators, and the types of relationships (direct and indirect) (Roldán \& Sánchez-Franco, 2012). We have used Smart PLS 3.2.7 software (Ringle, Wende \& Becker, 2015).

\section{Results}

According to Henseler, Hubona and Ray (2016) and Henseler (2018), we assess our PLS model in four stages: (1) Overall model, (2) measurement model, (3) structural model, and (4) predictive performance.

\subsection{Overall model: Tests of goodness-of-fit (GoF)}

Considering that our study has a confirmatory purpose, we begin the analysis of the estimated model focusing our interest on several measures of overall goodness-of-fit (GoF) (Henseler, 2018) available for PLS (Henseler, Hubona et al., 2016).

The evaluation of the standardized root mean square residual (SRMR) (Hu \& Bentler, 1998) index offers a satisfactory value of 0.0572 (Table 1), which is under the usual cut-off of 0.08 proposed by Hu and Bentler (1999). Additionally, we have carried out various tests of model fit (SRMR, $\mathrm{d}_{\mathrm{ULS}}, \mathrm{d}_{\mathrm{G}}$ ) by means of inference statistics based on bootstrap (Henseler, Hubona et al., 2016). Since these indices are under the bootstrap-based 95\% (HI95) percentile (Table 1), the discrepancy between the empirical and the model-implied correlation matrix is not significant. Therefore, the hypothesized model cannot be rejected because it is likely true (Henseler, 2017b). Consequently, the data do not contain more information than the model conveys (Henseler, Hubona et al., 2016).

\begin{tabular}{|l|c|r|}
\hline \multicolumn{3}{|c|}{ Estimated model } \\
\hline & Value & HI95 \\
\hline SRMR & 0.0572 & 0.0784 \\
\hline$d_{U L S}$ & 0.6227 & 1.1681 \\
\hline$d_{G}$ & 0.4349 & 0.6166 \\
\hline \multicolumn{3}{|c|}{ Saturated model } \\
\hline \multicolumn{3}{|c|}{ Value } \\
\hline SRMR & 0.0528 & HI95 \\
\hline$d_{U L S}$ & 0.5292 & 1.0048 \\
\hline$d_{G}$ & 0.4297 & 0.6041 \\
\hline
\end{tabular}

Table 1. Tests of model fit

\subsection{Measurement model}

We carry out a confirmatory composite analysis using overall model fit tests of the saturated model (Henseler, Hubona et al., 2016), which allow us to assess the external validity of the composites (Henseler, 2017a). The three measures of discrepancy between the empirical and the model-implied correlation matrix are below their corresponding HI95 values for the saturated model (Table 1), which means that the discrepancy is not significant. Therefore, we can assume that indicators form the composites according to the measurement model proposed (Henseler, 2017c). 
Then, we assess those composites estimated in Mode A (KMPerf and OP) where we expect that their manifest variables are correlated. In this case, usual measures of reliability and validity can be applied (Henseler, Ringle \& Sarstedt, 2016). In our study, both variables satisfy the usual and established requirements (Roldán \& SánchezFranco, 2012). First, individual item reliability is appropriate since loadings are greater than 0.707 (Table 2). Second, construct reliability is met since composite reliabilities are greater than 0.7 (Table 3). Besides, convergent validity is achieved because average variance extracted (AVE) measures are above 0.5 (Table 3). Finally, both constructs attain discriminant validity applying the comparison of the square root of AVE against correlations (Fornell \& Larcker criterium) (Table 3) and the $\mathrm{HTMT}_{85}$ criterion (Henseler, Ringle \& Sarstedt, 2015) (Table 4).

\begin{tabular}{|c|c|c|c|}
\hline Construct/Indicator & VIF & Weight & Loading \\
\hline \multicolumn{4}{|l|}{ Knowledge Management Practices (KMP)(Mode B) } \\
\hline Knowledge maintenance and protection & 1.463 & 0.2233 & 0.6773 \\
\hline External knowledge capturing & 1.33 & -0.0785 & 0.4356 \\
\hline Knowledge codification & 1.541 & $0.3978^{*}$ & 0.7913 \\
\hline Knowledge practices focused on the human factor & 1.548 & $0.6359 *$ & 0.8935 \\
\hline \multicolumn{4}{|c|}{ Knowledge Management Performance (KMPerf)(Mode A) } \\
\hline kmperf1 & & & 0.8756 \\
\hline kmperf2 & & & 0.9252 \\
\hline kmperf3 & & & 0.9254 \\
\hline kmperf4 & & & 0.8882 \\
\hline kmperf5 & & & 0.837 \\
\hline \multicolumn{4}{|l|}{ Information Technology Infrastructure (IT)(Mode B) } \\
\hline Communication and collaboration technologies & 1.944 & 0.5761 & 0.9232 \\
\hline Information storage and recovery technologies & 2.039 & 0.3405 & 0.8599 \\
\hline Business intelligence applications & 1.337 & 0.2598 & 0.6751 \\
\hline \multicolumn{4}{|l|}{ Organizational Performance (OP) (Mode A) } \\
\hline op1 & & & 0.8114 \\
\hline op2 & & & 0.8948 \\
\hline op3 & & & 0.8748 \\
\hline op4 & & & 0.9072 \\
\hline op5 & & & 0.9127 \\
\hline \multicolumn{4}{|l|}{ Innovation (I) } \\
\hline i1 & & & 1 \\
\hline \multicolumn{4}{|l|}{ Size $(\mathrm{S})$} \\
\hline s1 & & & 1 \\
\hline
\end{tabular}

Table 2. Measurement model

\begin{tabular}{|r|r|c|r|r|r|r|r|r|}
\hline \multicolumn{1}{|c|}{ CR } & \multicolumn{1}{|c|}{ AVE } & Construct & \multicolumn{1}{c|}{ KMP } & KMPerf & \multicolumn{1}{c|}{ ITI } & \multicolumn{1}{c|}{ OP } & I & S \\
\hline n.a. & n.a. & KMP & n.a. & & & & & \\
\hline 0.9505 & 0.7938 & KMPerf & 0.5229 & $\mathbf{0 . 8 9 1 0}$ & & & & \\
\hline n.a. & n.a. & IT & 0.5434 & 0.4656 & n.a. & & & \\
\hline 0.9453 & 0.7761 & OP & 0.2055 & 0.4575 & 0.3307 & $\mathbf{0 . 8 8 1 0}$ & & \\
\hline n.a. & n.a. & I & 0.3121 & 0.3322 & 0.2755 & 0.0753 & n.a. & \\
\hline n.a. & n.a. & S & 0.1578 & 0.1585 & 0.3715 & 0.2957 & 0.1026 & n.a. \\
\hline
\end{tabular}

Notes:

1) Diagonal elements (bold) are the square root of the variance shared between the constructs and their measures (AVE). Off-diagonal elements are the correlations between constructs. For discriminant validity, diagonal elements should be larger than off-diagonal elements.n.a.: non-applicable.

2) CR: Composite reliability; AVE: Average variance extracted.

3) KMP: Knowledge Management Practices; KMPerf: Knowledge Management Performance; IT: Information Technology Infrastructure; OP: Organizational Performance; I: Innovation; S: Size.

Table 3. Construct reliability, convergent validity and discriminant validity (Fornell \& Larcker criterion)

\begin{tabular}{|l|r|r|r|c|}
\cline { 2 - 5 } \multicolumn{1}{c|}{} & \multicolumn{1}{c|}{ KMPerf } & OP & I & S \\
\hline KMPerf & & & & \\
\hline OP & 0.4913 & & & \\
\hline I & 0.3392 & 0.0870 & 0.1026 & \\
\hline S & 0.1654 & 0.3080 & & \\
\hline
\end{tabular}

Notes:

1) KMPerf: Knowledge Management Performance; OP: Organizational Performance; I: Innovation; S: Size.

Table 4. Discriminant validity: Heterotrait-Monotrait Ratio (HTMT) 
Composites estimated in Mode B (KM practices and IT infrastructure) are assessed evaluating the discriminant validity, the potential multicollinearity, and the magnitude of weights. First, discriminant validity is achieved since correlations between components and the rest of the variables are less than 0.7 (Urbach \& Ahlemann, 2010). Second, given that the maximum variance inflation factor (VIF) value is 2.039, well below the threshold of 3.3 (Roldán \& Sánchez-Franco, 2012) (Table 2), we can assume there is no problem of multicollinearity between manifest variables of each composite. Finally, weights inform about how each item contributes to its composite. Hence, they allow these indicators to be arranged in order, according to their impact (Henseler, Ringle \& Sinkovics, 2009). Table 2 shows that knowledge practices focused on the human factor and knowledge codification represent the most important activities in the composition of the KM practices constructs. In addition, communication and collaboration technologies are the key applications in the IT infrastructure.

\subsection{Structural model}

In this stage, we assess the $R^{2}$ values of endogenous constructs, the algebraic sign, magnitude, significance and the $f$ values of the standardized regression coefficients (Hair, Hult, Ringle \& Sarstedt, 2017).

Figure 2 and Table 5 show the explained variance $\left(R^{2}\right)$ in the endogenous variables and the path coefficients. The $R^{2}$ value enables the predictive power of our model (in-sample prediction) for dependent constructs to be assessed. Thus, we achieve near moderate values of variance explained for KM performance and organizational performance variables, because their $R^{2}$ values are close to 0.33 (Chin, 2010) (Table 5).

To evaluate the significance of the direct effects of the path model, a bootstrapping (5,000 samples) process was carried out in order to obtain $t$-values and percentile confidence intervals (Roldán \& Sánchez-Franco, 2012). Considering data provided in Table 5, H1-H4 are supported, since the four direct relationships are positive and significant. These four links reach $f^{f}$ values above the minimum level of 0.02 (Chin, 2010). However, the effects described by $\mathrm{H} 5$ and $\mathrm{H} 6$ are not significant in addition to having $f$ values under 0.02 . This means that the IT infrastructure does not have a direct effect on the global performance variables, that is to say, organizational performance and innovation constructs. Meanwhile the firm size, as a control variable, has a significant influence on organizational performance. Finally, Table 5 shows the variance decomposed in each dependent component. We observe how KM practices explain $20.02 \%$ of the KM performance, while the IT infrastructure accounts for practically half of this figure. On the other hand, the KM performance is the main antecedent variable of the organizational performance.
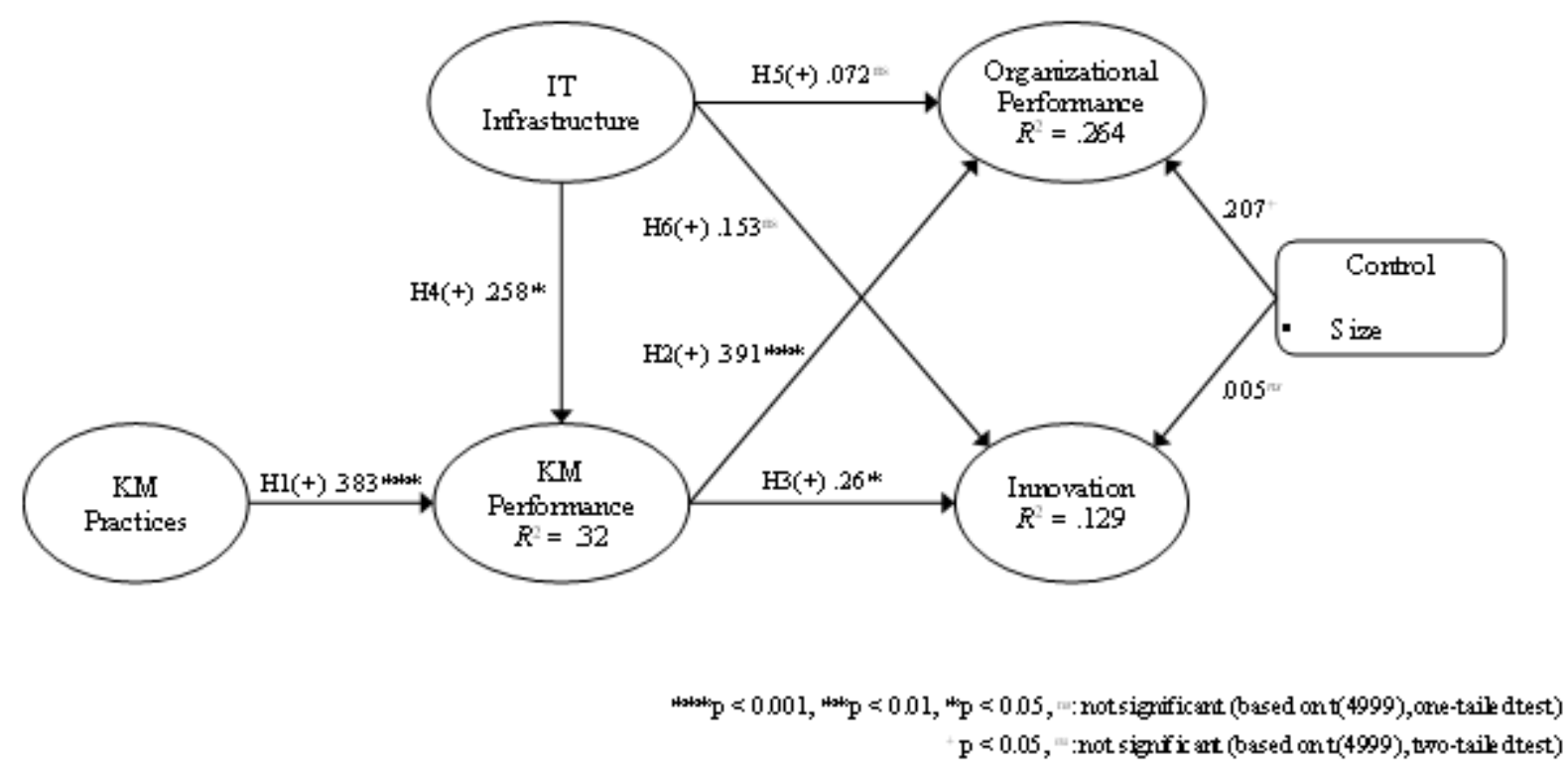

Figure 2. Structural model results 


\begin{tabular}{|c|c|c|c|c|c|c|}
\hline & Direct effect & $t$-value & $p$-value & CI & Explained variance & $f^{2}$ \\
\hline \multicolumn{7}{|l|}{$\begin{array}{l}\text { KMPerf } \\
R^{2}=0.320\end{array}$} \\
\hline $\mathrm{H} 1(+): \mathrm{KMP}$ & 0.383 & 3.654 & 0.000 & [0.231; 0.574] Sig. & $20.02 \%$ & 0.152 \\
\hline $\mathrm{H} 4(+): \mathrm{IT}$ & 0.258 & 2.236 & 0.013 & {$[0.065 ; 0.441]$ Sig. } & $11.99 \%$ & 0.069 \\
\hline \multicolumn{7}{|l|}{ OP } \\
\hline $\mathrm{H} 2(+):$ KMPerf & 0.391 & 3.184 & 0.001 & [0.175; 0.581] Sig. & $17.90 \%$ & 0.163 \\
\hline $\mathrm{H} 5(+): \mathrm{IT}$ & 0.072 & 0.559 & 0.288 & {$[-0.126 ; 0.300]$ NSig. } & $2.37 \%$ & 0.005 \\
\hline $\mathrm{S}$ & 0.207 & 2.287 & 0.022 & {$[0.003 ; 0.364]$ Sig. } & $6.12 \%$ & 0.050 \\
\hline \multicolumn{7}{|l|}{$\begin{array}{l}I \\
R^{2}=0.129\end{array}$} \\
\hline H3(+)KMPerf & 0.260 & 2.176 & 0.015 & [0.061; 0.455] Sig. & $8.65 \%$ & 0.061 \\
\hline H6(+): IT & 0.153 & 0.811 & 0.209 & {$[-0.157 ; 0.458]$ NSig. } & $4.20 \%$ & 0.019 \\
\hline S & 0.005 & 0.056 & 0.956 & {$[-0.173 ; 0.152]$ NSig. } & $0.05 \%$ & 0.000 \\
\hline
\end{tabular}

Notes:

1) CI: Percentile confidence interval. Bootstrapping based on $n=5000$ subsamples.

2) A one-tailed test for a t Student distribution (CI 90\%) is applied to evaluate hypothesized paths. Effects from the control variable are assessed by applying a two-tailed test (CI 95\%). Sig. describes a significant direct effect at 0.05 ; NSig. denotes a non-significant direct effect at 0.05 .

3) KMP: Knowledge Management Practices; KMPerf: Knowledge Management Performance; IT: Information Technology Infrastructure; OP: Organizational Performance; I: Innovation; S: Size.

Table 5. Effects on endogenous variables

Finally, a post-hoc indirect effect analysis has been performed. Applying the analytical approach proposed by Nitzl, Roldan and Cepeda-Carrion (2016), we test two indirect effects. As Table 6 shows, both indirect relationships are significant. This means that the KM performance mediates the influence of IT infrastructure on performance variables, that is, organizational performance and innovation. Therefore, considering that the direct relationships described by $\mathrm{H} 5$ and $\mathrm{H} 6$ are not significant, our results seem to indicate that the influence of IT infrastructure on performance variables is not direct but indirect. Consequently, the KM performance variable is a key mediator in these indirect links.

\begin{tabular}{|c|c|c|c|c|}
\hline Indirect effect & Point estimate & \multicolumn{2}{|c|}{ CI } & \\
\hline & & Lower & Upper & \\
\hline IT-->KMPerf-->OP & 0.1008 & 0.0075 & 0.2191 & Significant \\
\hline IT--> KMPerf-->I & 0.0671 & 0.0003 & 0.1667 & Significant \\
\hline
\end{tabular}

1) CI: Percentile confidence interval. Bootstrapping based on $n=5000$ subsamples.

2) KMPerf: Knowledge Management Performance; IT: Information Technology Infrastructure; OP: Organizational Performance; I: Innovation.

Table 6. Indirect effects of IT infrastructure

\subsection{Evaluation of the predictive performance}

The predictive performance of a model "refers to a model's ability to generate accurate predictions of new observations, where new can be interpreted temporally" (Shmueli \& Koppius, 2011, p. 555). In this way, the predictive ability (out-of-sample prediction) has been evaluated using cross-validation with holdout samples (Evermann \& Tate, 2016). We have applied the PLS predict algorithm (Shmueli et al, 2016) included in the SmartPLS software version 3.2.7. (Ringle et al., 2015), as well as the new measures of predictive performance for a specific model developed by the SmartPLS team (SmartPLS, 2017) (cf. also Felipe, Roldán \& Leal-Rodríguez, 2017).

At the construct level, we obtain good results for KM performance and organizational performance variables, since their $Q^{2}$ values are above 0 (Table 7). However, our model does not show predictive power for the innovation construct. An equivalent result is attained at the indicator level, where the PLS-SEM results generally show lower prediction errors (e.g., in terms of RMSE or MAE), and greater $Q^{2}$ values, than those values provided by the linear regression model (LM) for the manifest variables of KM performance and organizational performance. 
As a conclusion, we found evidence that our research model has predictive power (out-of-sample prediction) to predict values for new observations of KM performance and organizational performance variables using data that are not included in the dataset used to test the research model (Dolce, Esposito Vinzi \& Lauro, 2017).

\begin{tabular}{|c|c|c|c|c|c|c|c|c|c|c|c|}
\hline \multicolumn{12}{|c|}{ Construct Prediction Summary } \\
\hline & $Q^{2}$ & & & & & & & & & & \\
\hline KMPerf & 0.197 & & & & & & & & & & \\
\hline OP & 0.142 & & & & & & & & & & \\
\hline $\mathbf{I}$ & -0.298 & & & & & & & & & & \\
\hline \multicolumn{12}{|c|}{ Indicator Prediction Summary } \\
\hline \multicolumn{4}{|c|}{ PLS } & \multicolumn{4}{|c|}{$\mathbf{L M}$} & \multicolumn{4}{|c|}{ PLS-LM } \\
\hline & RMSE & MAE & $Q^{2}$ & & RMSE & MAE & $Q^{2}$ & & RMSE & MAE & $Q^{2}$ \\
\hline kmperf1 & 0.701 & 0.506 & 0.248 & kmperf1 & 0.72 & 0.552 & 0.206 & kmperf1 & -0.019 & -0.046 & 0.042 \\
\hline kmperf2 & 0.715 & 0.547 & 0.238 & kmperf2 & 0.751 & 0.58 & 0.16 & kmperf2 & -0.036 & -0.033 & 0.078 \\
\hline kmperf3 & 0.823 & 0.631 & 0.116 & kmperf3 & 0.841 & 0.661 & 0.078 & kmperf3 & -0.018 & -0.03 & 0.038 \\
\hline kmperf4 & 0.844 & 0.65 & 0.141 & kmperf4 & 0.897 & 0.688 & 0.029 & kmperf4 & -0.053 & -0.038 & 0.112 \\
\hline kmperf5 & 0.819 & 0.631 & 0.137 & kmperf5 & 0.812 & 0.635 & 0.151 & kmperf5 & 0.007 & -0.004 & -0.014 \\
\hline op1 & 1.016 & 0.797 & 0.057 & op1 & 1.083 & 0.849 & -0.073 & op1 & -0.067 & -0.052 & 0.13 \\
\hline op2 & 0.879 & 0.658 & 0.098 & op2 & 0.951 & 0.724 & -0.056 & op2 & -0.072 & -0.066 & 0.154 \\
\hline op3 & 1 & 0.735 & 0.002 & op3 & 1.072 & 0.804 & -0.148 & op3 & -0.072 & -0.069 & 0.15 \\
\hline op4 & 0.889 & 0.642 & 0.061 & op4 & 0.959 & 0.715 & -0.094 & op4 & -0.07 & -0.073 & 0.155 \\
\hline op5 & 0.885 & 0.641 & 0.095 & op5 & 0.937 & 0.7 & -0.014 & op5 & -0.052 & -0.059 & 0.109 \\
\hline i1 & 1.117 & 0.911 & 0.047 & i1 & 1.116 & 0.879 & 0.049 & i1 & 0.001 & 0.032 & -0.002 \\
\hline
\end{tabular}

1) KMPerf: Knowledge Management Performance; OP: Organizational Performance; I: Innovation.

2) PLS: Partial least squares path model; LM: Linear regression model; RMSE: Root mean squared error; MAE: Mean absolute error.

Table 7. PLS predict assessment

\section{Discussion and conclusions}

\subsection{Theoretical implications}

This research offers five core contributions for theory and research. First, KM practices affect KM performance. The most important KM practices are based on the human factor, while the least important is the exterior knowledge capture. The practices focused on the human factor are implemented to generate and share knowledge, encouraging socialization between individuals in the traditional processes of knowledge creation and transfer that took place through face-to-face interaction, planned, or ad hoc (Alavi \& Leidner, 1999). Therefore, these types of practices have a greater importance in predicting success in KM performance. This review is in line with Inkinen (2016) who pointed out highly knowledge-intensive HRM practices are a central vehicle to manage organizational knowledge resources.

Second, although there are studies that have concluded that it is difficult to evaluate KM performance, in this research the positive influence of KM performance on organizational performance has been tested. In line with the comments made by Mills and Smith (2011), the performance of knowledge resources (e.g., organizational structure, the application of knowledge) is directly related to organizational performance.

Third, it has been shown that KM performance contributes to innovation development in the organization. Innovation reaches out to benefit from the extra-firm resources that are available through both individual and organizational relationships (Inkinen, 2015). According to Snowden (2003), one of the main objectives of KM is to create the conditions for innovation. In this sense, our contribution emphasizes the importance of networking people in knowledge sharing. When the knowledge is integrated and used effectively, it can improve organizational innovation. In the same vein, the study of Inkinen, Kianto and Vanhala (2015) showed how various types of $\mathrm{KM}$ practices impact on the firm's innovation performance and adds to a better understanding of how knowledge should be managed for organizational benefit. 
Fourth, another key finding is that the adoption of an IT infrastructure for KM has a positive effect on KM performance. While the technology itself is not KM, it can act to stimulate and support knowledge exchange processes, making them more operational and effective.

However, as suggested by Hansen and Thompson (2002), companies can maintain databases, engage in datamining, implement expert systems, provide access to email and the Internet, develop intranets and extranets, provide collaborative tools - and still lack the ability to capitalize on their knowledge. Following Alavi and Leidner (2001), the processes of creation, storage, retrieval and transfer of knowledge does not necessarily lead to greater organizational performance. It is the effective application of this knowledge which can actually lead to these results for the organization.

Fifth, Powell and Dent-Micallef (1997) state that IT alone cannot be considered as a strategic resource, but it is through the KM performance that IT has an impact on organizational performance and innovation. In terms of sustainability, the IT competitive advantages lie in IT- related management skills, not in the technology itself (Mata, Fuerst \& Barney, 1995). This idea has been confirmed in subsequent studies (e.g., Teo \& Ranganathan, 2003), in which the importance of IT capabilities is highlighted.

IT is widely held to be increasingly homogeneous and hardly a developed "measure" within the company, due to their complexity (Smith, Vasudevan \& Tanniru, 1996), likely to become a product through imitation and acquisition (Clemons \& Row, 1991).

\subsection{Practical implications}

Our study has several important managerial and practical implications. First, firms should invest in KM practices that are needed for technology-oriented utilization and development of knowledge, the practices focused on the human factor are particularly important. These practices are implemented to promote socialization among individuals, fostering the generation and sharing of knowledge. Managers should seek employees who have suitable skills that support and generates a culture of trust and learning. Human capital management is a driver to increase KM performance, employees involvement to develop new notions and share knowledge which also enhances innovative results.

Second, although there is an inclination to state that a successful KM should contribute to better business results, this still presents a vivid debate. From our results, it is observed that good results in KM portend good overall results in the organization. It can be predicted that a company with a good KM performance has greater organizational performance and innovation, and the managers should focus resources to obtain better KM practices and improve IT infrastructure.

Finally, it is important to have the technological tools that support the processes for integrating the KM cycle. However, this is not the most critical aspect for KM. These technologies may sometimes be a necessary but not sufficient condition for the implementation of KM. Managers should invest in complementary intangible assets which could leverage a positive effect of IT on organizational performance and innovation, so the company can create unique capabilities that can be a source of sustainable competitive advantage.

\subsection{Limitations and future research}

This research presents the following limitations. The measures used to evaluate some constructs are derived measures, so we did not use scales specifically designed to assess these variables (KM practices and IT infrastructure). Another limitation is that the measures are based on the perceptions of the participants in the study. However, the use of measures based on perceptions is not necessarily seen as a weakn ess. In fact,it has clear findings of convergence between subjective performance measures and objective measures (Venkatraman \& Ramanajunam, 1986). Besides, as we use a single informant there is the possibility that he or she could create a real connection between the variables (Podsakoff, MacKenzie, Lee \& Podsakoff, 2003).

As future research lines, alternative research designs could be followed. For instance, a longitudinal approach would allow studying the evolution of KM in the company. On the other hand, qualitative studies would allow delving further into the relationships described in our study. 


\section{Declaration of Conflicting Interests}

The authors declared no potential conflicts of interest with respect to the research, authorship, and/or publication of this article.

\section{Funding}

This research was supported by the Junta de Andalucia (Consejería de Economia, Innovación y Ciencia), Spain (Proyectos de investigación de excelencia: P06-SEJ-01994, P10-SEJ-6081).

\section{References}

Alavi, M., Kayworth, T., \& Leidner, D.E. (2006). An Empirical Examination of the Influence of Organizational Culture on Knowledge Management Practices. Journal of Management Information Systems, 22(3), 191-224. https://doi.org/10.2753/MIS0742-1222220307

Alavi, M., \& Leidner, D.E. (1999). Knowledge Management Systems: Issues, Challenges and Benefits. Communications of AIS 7, 1-37.

Alavi, M., \& Leidner, D.E. (2001). Review: Knowledge Management and Knowledge Management Systems: Conceptual Foundations and Research Issues. MIS Quarterly, 25(1), 107-136. https://doi.org/10.2307/3250961

Altarawneh, I.I, \& Altarawneh, K. (2017).Knowledge Management Practices and Intellectual Capital: A Case from Jordan. International Journal of Business, 22(4), 341-367.

Argote L., Mc Evily, B., \& Reagans, R. (2003). Managing Knowledge in Organizations: An Integrative Framework and Review of Emerging Themes. Management Science, 49(4), 571-582.

https://doi.org/10.1287/mnsc.49.4.571.14424

Asaad, Z., \& Marane, B. (2016, October). How Does Information Technology Capability Shape the Relationship between Organizational Culture and Innovation Capability in Manufacturing Sectors?. 17th International Scientific Conference on Economic and Social Development, Warsaw, Poland.

Brynjolfsson, E., \& Hitt, L. (1996). Paradox Lost? Firm-Level Evidence on the Return to Information Systems. Management Science, 42(4), 541-558. https://doi.org/10.1287/mnsc.42.4.541

Chadha, S.K., \& Saini, R. (2014). Information Technology Support to Knowledge Management Practices: A Structural Equation Modeling Approach. IUP Journal of Knowledge Management, 12(1), 39-52.

Chin, W.W. (2010). How to Write Up and Report PLS Analyses. In V. Esposito Vinzi, W.W. Chin, J. Henseler, \& H. Wang (Eds.), Handbook of Partial Least Squares (pp. 655-690). Berlin Heidelberg: Springer-Verlag. https://doi.org/10.1007/978-3-540-32827-8_29

Choi, S., Lee, H., \& Yoo, Y. (2010). The Impact of Information Technology and Transactive Memory Systems on Knowledge Sharing, Application and Team Performance: A Field Study. MIS Quarterly, 34(4), 855-870. https://doi.org/10.2307/25750708

Chong, S.H., Salleh, K, Ahmad, S.N.S., \& Sharifuddin, S.S.O. (2011). KM Implementation in a Public Sector Accounting Organization: An Empirical Investigation. Journal of Knowledge Management, 15(3), 497-512. https://doi.org/10.1108/13673271111137457

Cooper, L.P. (2003). A Research Agenda to Reduce Risk in New Product Development through Knowledge Management: A Practitioner Perspective. Journal of Engineering and Technology Management, 20(1-2), 117-140. https://doi.org/10.1016/S0923-4748(03)00007-9

CWA 14924-1. (2004). European Guide to good Practice in Knowledge Management. Part 1: Knowledge management framework. ICS 03.100.99.

CWA 14924-2. (2004). European Guide to good Practice in Knowledge Management. Part 2: Organizational culture. ICS 03.100.99.

CWA 14924-3. (2004). European Guide to good Practice in Knowledge Management. Part 3: SME Implementation. ICS 03.100.99. 
CWA 14924-4. (2004). European Guide to Good Practice in Knowledge Management. Part 4: Guideline for Measurnig. ICS 03.100.99.

CWA 14924-5. (2004). European Guide to Good Practice in Knowledge Management. Part 5: KM Terminology. ICS 03.100.99.

Daghfous A., \& White G.R. (1994). Information and innovation: a comprehensive representation. Research Policy, 23(3), 267-280. https://doi.org/10.1016/0048-7333(94)90038-8

Darroch, J. (2005). Knowledge Management, Innovation and Firm Performance. Journal of Knowledge Management, 9(5), 101-115. https://doi.org/10.1108/13673270510602809

Davenport, T.H. (1999). Knowledge Management and the Broader Firm: Strategy, Advantage, and Performance. In J. Liebowitz (Ed.), Knowledge Management Handbook (pp. 1-11). Boca Raton, FL: CRC Press.

Davenport, T.H., \& Prusak, L. (1998). Working knowledge: How Organizations Manage what they Know. Harvard Business School Press, Boston, MA, USA. https://doi.org/10.1145/347634.348775

Dewett, T., \& Jones, G.R. (2001). The Role of Information Technology in the Organization: A Review, Model, and Assessment. Journal of Management, 27(3), 313-346. https://doi.org/10.1177/014920630102700306

Dolce, P., Esposito Vinzi, V., \& Lauro, C. (2017). Predictive Path Modeling Through PLS and Other Component-Based Approaches: Methodological Issues and Performance Evaluation. In H. Latan \& R. Noonan (Eds.), Partial Least Squares Path Modeling (pp. 153-172). Cham: Springer International Publishing. https://doi.org/10.1007/978-3-319-64069-3_7

Donate, M., \& Guadamillas, F. (2007). The Relationship between Innovation and Knowledge Strategies: Its Impacts on Business Performance. International Journal of Knowledge Management Studies, 1(3/4), 388-422. https://doi.org/10.1504/IJKMS.2007.012532

Durmusoglu, S.S., \& Barczak, G. (2011). The Use of Information Technology Tools in New Product Development Phases: Analysis of Effects on New Product Innovativeness, Quality, and Market Performance. Industrial Marketing Management, 40(2), 321-330. https://doi.org/10.1016/j.indmarman.2010.08.009

Earl, L. (2003). Knowledge Management in Practice in Canada, 2001. Working paper Science, Innovation and Electronic Information Division Statistics Canada Catalogue no. 88F0006XIE - No. 007.

Earl, L. (2005). Knowledge Sharing Succeeds: How Selected Service Industries Rated the Importance of Using Knowledge Management Practices to their Success. Working paper Science, Innovation and Electronic Information Division Statistics Canada Catalogue no. 88F0006XIE - No. 004. ISSN: 1706-8967 .ISBN: 0-662-39348-1.

Elenkov, D.S. (2002). Effects of Leadership on Organizational Performance in Russian Companies. Journal of Business Research, 55(6), 467-480. https://doi.org/10.1016/S0148-2963(00)00174-0

Evermann, J., \& Tate, M. (2016). Assessing the Predictive Performance of Structural Equation Model Estimators. Journal of Business Research, 69(10), 4565-4582. https://doi.org/10.1016/j.jbusres.2016.03.050

Garvin, D.A. (1993). Building a Learning Organization. Harvard Business Review, 71(4), 78-91.

Felipe, C.M., Roldán, J.L., \& Leal-Rodríguez, A.L. (2017). Impact of Organizational Culture Values on Organizational Agility. Sustainability, 9(12), 2354. https://doi.org/10.3390/su9122354

Gold, A.H., Malhotra, A., \& Segars, A.H. (2001). Knowledge Management: An Organizational Capabilities Perspective. Journal of Management Information Systems, 18(1), 185-214.

https://doi.org/10.1080/07421222.2001.11045669

Grant, R.M. (1991). Contemporary Strategy Analysis: Concepts, Techniques, Applications. Cambridge, MA. Blackwell.

Grant, R.M. (1996). Toward a Knowledge-Based Theory of the Firm. Strategic Management Journal, 17(7), 109-122. https://doi.org/10.1002/smj.4250171110 
Hair, J.F.J., Hult, G.T.M., Ringle, C.M., \& Sarstedt, M. (2017). A Primer on Partial Least Squares Structural Equation Modeling (PLS-SEM) (2nd ed.). Thousand Oaks, CA: SAGE Publications.

Handzic, M. (2015). A descriptive analysis of knowledge management research: Period from 1997 to 2012. In E. Bolisani \& M. Handzic (Eds.), Advances in Knowledge Management: Celebrating 20 years of research and practice (pp. 45-64). Switzerland: Springer International Publishing.

Hansen, J.I., \& Thompson, C.A. (2002). Knowledge Management: When People, Process, and Technology Converge. LIMRA's MarketFacts Quarterly, 21(2), 14-21.

Hansen, M.T., Nohria, N., \& Tierney, T. (1999). What's your Strategy for Managing Knowledge?. Harvard Business Review, 77(2), 106-116.

Haque, A, \& Anwar, S. (2012). Linking Top Management Support and IT Infrastructure with Organizational Performance: Mediating Role of Knowledge Application. Canadian Social Science, 8(1), 121-129.

Henseler, J. (2017a). Bridging Design and Behavioral Research with Variance-Based Structural Equation Modeling. Journal of Advertising, 46(1), 178-192. https://doi.org/10.1080/00913367.2017.1281780

Henseler, J. (2017b). Adanco 2.0.1. User Manual. KG, Kleve, Germany: Composite Modeling GmbH \& Co.

Henseler, J. (2017c). Partial Least Squares Path Modeling. In K. H. Leeflang, P. S., Wieringa, J. E., Bijmolt, T.H., \& Pauwels (Ed.), Advanced Methods for Modeling Markets (pp. 361-381). Springer International Publishing. https://doi.org/10.1007/978-3-319-53469-5_12

Henseler, J. (2018). Partial Least Squares Path Modeling: Quo Vadis?. Quality \& Quantity, 52(1), 1-8. https://doi.org/10.1007/s11135-018-0689-6

Henseler, J., Hubona, G., \& Ray, P.A. (2016). Using PLS Path Modeling in New Technology Research: Updated Guidelines. Industrial Management \& Data Systems, 116(1), 2-20. https://doi.org/10.1108/IMDS-09-2015-0382

Henseler, J., Ringle, C.M., \& Sarstedt, M. (2015). A New Criterion for Assessing Discriminant Validity in Variance-Based Structural Equation Modeling. Journal of the Academy of Marketing Science, 43(1), 115-135. https://doi.org/10.1007/s11747-014-0403-8

Henseler, J., Ringle, C.M., \& Sarstedt, M. (2016). Testing Measurement Invariance of Composites Using Partial Least Squares. International Marketing Review, 33(3), 405-431. https://doi.org/10.1108/IMR-09-2014-0304

Henseler, J., Ringle, C.M., \& Sinkovics, R.R. (2009). The Use of Partial Least Squares Path Modeling in International Marketing. In J. Henseler, C. M. Ringle, \& R. R. Sinkovics (Eds.), Advances in International Marketing, 20, 277-319. Bingley: Emerald Group Publishing. https://doi.org/10.1108/S14747979(2009)0000020014

Ho, C-T. (2009). The Relationship Between Knowledge Management Enablers and Performance. Industrial Management and Data Systems, 109(1), 98-117. https://doi.org/10.1108/02635570910926618

Holsapple, C., \& Joshi, K.A. (2003). Knowledge management ontology. In C.W. Holsapple (Ed.), Handbook on Knowledge Management (Vol 1: Knowledge Matters pp 89-128). Springer-Verlag, Heidelberg, Germany.

Hu, L., \& Bentler, P.M. (1998). Fit Indices in Covariance Structure Modeling: Sensitivity to Underparameterized Model Misspecification. Psychological Methods, 3(4), 424-453. https://doi.org/10.1037/1082-989X.3.4.424

Hu, L., \& Bentler, P.M. (1999). Cutoff Criteria for Fit Indexes in Covariance Structure Analysis: Conventional Criteria Versus New Alternatives. Structural Equation Modeling: A Multidisciplinary Journal, 6(1), 1-55. https://doi.org/10.1080/10705519909540118

Inkinen, H. (2015). Review of Empirical Research on Intellectual Capital and Firm Performance. Journal of Intellectual Capital, 16(3), 518-565. https://doi.org/10.1108/JIC-01-2015-0002

Inkinen, H.T., Kianto, A., \& Vanhala, M. (2015). Knowledge Management Practices and Innovation Performance in Finland. Baltic Journal of Management, 10(4), 432-455. https://doi.org/10.1108/BJM-10-2014-0178 
Inkinen, H. (2016). Review of Empirical Research on Knowledge Management Practices and Firm Performance. Journal of Knowledge Management, 20(2), 230-257. https://doi.org/10.1108/JKM-09-2015-0336

Inkpen, A., \& Crossan. M.M. (1995). Believing is Seeing: Organizational Learning in Joint Ventures. Journal of Management Studies, 32(5), 595-618. https://doi.org/10.1111/j.1467-6486.1995.tb00790.x

Kelly, M. (1994). Productivity and Information Technology: The Elusive Connection”. Management Science, 40(11), 1406-1425. https://doi.org/10.1287/mnsc.40.11.1406

Kerssens-van Drongelen C., Weerd-Nederhof, P.C., \& Fisscher, O.A. (1996). Describing the Issues of Knowledge Management in R\&D: Towards a Communication and Analysis Tool. R\&D Management, 26(3), 213-229. https://doi.org/10.1111/j.1467-9310.1996.tb00957.x

Kettinger, W., Grover, V., Guha, S., \& Segars, A. (1994). Strategic Information Systems Revisited: A Study in Sustainability and Performance. MIS Quarterly, 18(1), 31-58. https://doi.org/10.2307/249609

Keying, Z., Rui, Z., \& Xiaoli, Z. (2010). Research on the Influence of Knowledge Management Capability to Intellectual Property Risk in Enterprise Independent Innovation. Proceedings of the International Conference on EBusiness and E-Government, ICEE, 5592723 (pp.1915-1919). https://doi.org/10.1109/ICEE.2010.484

King, W. (2005). Communication and Information Processing as a Critical Success Factor in the Effective Knowledge Organisation. International Journal of Business Information Systems, 1(1/2), 31-52. https://doi.org/10.1504/IJBIS.2005.007399

Kleis, L., Chwelos, P., Ramirez, R.V., \& Cockburn, I. (2012). Information Technology and Intangible Output: The Impact of IT Investment on Innovation Productivity. Information Systems Research, 23(1), 42-59. https://doi.org/10.1287/isre.1100.0338

Leonard-Barton, D. (1995). Wellsprings of knowledge: Building and sustaining the sources of innovation. Boston, MA, USA: Harvard Business School Press.

Loveman, W. (1994). An Assessment of Productivity Impact on Information Technologies. In T. J. Allen, M.S. Scott (eds.), Information Technology and the Corporation of the 1990's: Research Studies (pp. 84-110) Cambridge, MA.: MIT Press.

Lucas, H.C. (1999). Information Technology and the Productivity Paradox. New York: Oxford University Press.

Luftman, J.N., Lyytinen, K., \& Ben-Zvi, T. (2017). Enhancing the Measurement of Information Technology (IT) Business Alignment and its Influence on Company Performance. Journal of Information Technology, 32(1), 26-46. https://doi.org/10.1057/jit.2015.23

Mahmood, M.A., \& Mann, G.J. (1993). Measuring the Organizational Impact of Information Technology Investment: An Exploratory Study. Journal of Management Information Systems, 10(1), 97-122. https://doi.org/10.1080/07421222.1993.11517992

Mao, H., Liu, S., Zhang, J., \& Deng, Z. (2016). Information Technology Resource, Knowledge Management Capability, and Competitive Advantage: The Moderating Role of Resource Commitment. International Journal of Information Management, 36(6 Part A), 1062-1074. https://doi.org/10.1016/j.ijinfomgt.2016.07.001

Mata, F.J., Fuerst, W.L., \& Barney, J. (1995). Information Technology and Sustained Competitive Advantage: A Resource-Based Analysis. MIS Quarterly, 19(4), 487-505. https://doi.org/10.2307/249630

Migdadi, M. (2009). Knowledge Management Enablers and Outcomes in the Small-and-Medium Sized Enterprises. Industrial Management \& Data Systems, 109(6), 840-858. https://doi.org/10.1108/02635570910968072

Mills, A.M., \& Smith, T.A. (2011). Knowledge Management and Organizational Performance: A Decomposed View. Journal of Knowledge Management, 15(1), 156-171. https://doi.org/10.1108/13673271111108756

Nitzl, C., \& Chin, W.W. (2017). The Case of Partial Least Squares (PLS) Path Modeling in Managerial Accounting Research. Journal of Management Control, 28(2), 137-156. https://doi.org/10.1007/s00187-017-0249-6 
Nitzl, C., Roldan, J.L., Cepeda-Carrion, G. (2016). Mediation Analysis in Partial Least Squares Path Modeling: Helping Researchers Discuss More Sophisticated Models. Industrial Management \& Data Systems, 116(9), 1849-1864. https://doi.org/10.1108/IMDS-07-2015-0302

Nonaka, I., Toyama, R., \& Byosiére, P. (2001). A Theory of Organizational Knowledge Creation: Understanding the Dynamic Process of Creating Knowledge. In M. Dierkes, A. Berthoin, J. Child, \& I. Nonaka (Eds.), Handbook of Organizational Learning and Knowledge (pp. 491-517). New York, NY, USA: Oxford University Press.

O’Leary, D.E. (2003). Technologies for Knowledge Storage and Assimilation. In C.W. Holsale (Ed.), Handbook on Knowledge Management (Vol 2: Knowledge Directions, pp. 29-46). Heidelberg, Germany: Springer-Verlag.

OECD. (2005). Oslo Manual: Guidelines for Collecting and Interpreting Innovation Data. Paris: 3rd OECD Publishing. https://doi.org/10.1787/9789264013100-en

Pawlosky, P., Forslin, J., \& Reinhardt, R. (2001). Practices and Tools of Organizational Learning. In M. Dierkes, A. Berthoin, J. Child, I., \& Nonaka (Eds.), Handbook of Organizational Learning and Knowledge (pp. 775-793) Oxford University Press, New York, NY, USA.

Podsakoff, P.M., MacKenzie, S.B., Lee, J.-Y., \& Podsakoff, N.P. (2003). Common method biases in behavioral research: a critical review of the literature and recommended remedies. The Journal of Applied Psychology, 88(5), 879-903. http://doi.org/10.1037/0021-9010.88.5.879

Powell, C.T., \& Dent-Micallef, A. (1997). Information Technology as Competitive Advantage: The Role of Human, Business, and Technology Resources. Strategic Management Journal, 18(5), 375-405. http://dx.doi.org/10.1002/(SICI)1097-0266(199705)18:5<375::AID-SMJ876>3.0.CO;2-7

Rampersad, G.C., Plewa, C., \& Troshani, I. (2012). Investigating the Use of Information Technology in Managing Innovation: A case study from a University Technology Transfer Office. Journal of Engineering and Technology Management, 29(1), 3-21. https://doi.org/10.1016/j.jengtecman.2011.09.002

Razmerita, L., Kirchner, K., \& Sudzina, F. (2009). Personal Knowledge Management: The Role of Web 2.0 Tools for Managing Knowledge at Individual and Organisational Levels. Online Information Review, 33(6), 1021-1039. https://doi.org/10.1108/14684520911010981

Real, J.C., Leal, A., \& Roldán, J.L. (2006). Information Technology as a Determinant of Organizational Learning and Technological Distinctive Competencies. Industrial Marketing Management, 35(4), 505-521. https://doi.org/10.1016/j.indmarman.2005.05.004

Riege, A. (2005). Three-Dozen Knowledge-Sharing Barriers Managers Must Consider. Journal of Knowledge Management, 9(3), 19-33. https://doi.org/10.1108/13673270510602746

Rigdon, E.E. (2013). Partial Least Squares Path Modeling. In G. R. Hancock \& R. O. Mueller (Eds.), Structural Equation Modeling: A Second Course (2nd ed., pp. 81-116). Charlotte, NC: Information Age.

Rigdon, E.E., Sarstedt, M., \& Ringle, C.M. (2017). On Comparing Results from CB-SEM and PLS-SEM: Five Perspectives and Five Recommendations. Marketing ZFP, 39(3), 4-16. https://doi.org/10.15358/0344-1369-2017$3-4$

Ringle, C.M., Wende, S., \& Becker, J. (2015). SmartPLS 3. Bönningstedt: SmartPLS. Retrieved from: http://www.smartpls.com/

Roldán, J.L., \& Sánchez-Franco, M.J. (2012). Variance-Based Structural Equation Modeling: Guidelines for Using Partial Least Squares in Information Systems Research. In M. Mora, O. Gelman, A. Steenkamp, \& M. Raisinghani (Eds.), Research Methodologies, Innovations and Philosophies in Software Systems Engineering and Information Systems (pp. 193-221). Hershey PA: IGI Global. https://doi.org/10.4018/978-1-4666-0179-6.ch010

Sarstedt, M., Hair, J.F., Ringle, C.M., Thiele, K.O., \& Gudergan, S.P. (2016). Estimation issues with PLS and CBSEM: Where the bias lies!. Journal of Business Research, 69(10), 3998-4010. 
Scarbrough, H. (2003). Knowledge Management, HRM and the Innovation Process. International Journal of Manpower, 24(5), 501-516. https://doi.org/10.1108/01437720310491053

Shmueli, G., Ray, S., Velasquez Estrada, J.M., \& Chatla, S.B. (2016). The elephant in the room: Predictive performance of PLS models. Journal of Business Research, 69(10), 4552-4564.

https://doi.org/10.1016/j.jbusres.2016.03.049

Shmueli, G., \& Koppius, O. (2011). Predictive Analytics in Information Systems Research. MIS Quarterly, 35(3), 553-572. https://doi.org/10.2307/23042796

Serenko, A., Bontis, N., \& Hull, E. (2016). An Application of the Knowledge Management Maturity Model: The Case of Credit Unions. Knowledge Management Research \& Practice, 14(3), 338-352.

https://doi.org/10.1057/kmrp.2014.37

Snowden, D. (2003). Innovation as an Objective of Knowledge Management. Part I: The Landscape of Management. Knowledge Management Research \& Practice, 1(2), 113-119.

https://doi.org/10.1057/palgrave.kmrp.8500014

SmartPLS. (2017). PLS Predict | SmartPLS. Retrieved October 10, 2017, from: https://www.smartpls.com/documentation/algorithms-and-techniques/predict

Stanovcic, T, Pekovic, S., \& Bouziri, A. (2015). The Effect of Knowledge Management on Environmental Innovation. Baltic Journal of Management, 10(4), 413-431. https://doi.org/10.1108/BJM-01-2015-0012

Starbuck, W. (1992). Learning by Knowledge-Intensive Firms. Journal of Management Studies, 29(6), 713-740. https://doi.org/10.1111/j.1467-6486.1992.tb00686.x

Swan, J., Newell, S., Scarbrough, H., \& Hislop, D. (1999). Knowledge Management and Innovation: Networks and Networking. Journal of Knowledge Management, 3(4), 262-275. https://doi.org/10.1108/13673279910304014

Teo, T.S.H., \& Ranganathan, C. (2003). Leveraging IT Resources and Capabilities at the Housing and Development Board. Journal of Strategic Information Systems, 12(3), 229-249.

https://doi.org/10.1016/j.jsis.2003.09.002

Turban, E., Aronson, E., Liang, T-P, Sharda, R., Delen, D., \& King, D. (2010). Decision Support and Business Intelligence Systems. New Jersey, USA: Prentice Hall.

Tushman, M.L. (1977). Special Boundary Roles in the Innovation Process. Administrative Science Quarterly, 22(4), 587-605. https://doi.org/10.2307/2392402

Urbach, N., \& Ahlemann, F. (2010). Structural Equation Modeling in Information Systems Research Using Partial Least Squares. Journal of Information Technology Theory and Application, 11(2), 5-40.

Venkatraman, N., \& Ramanujam, V. (1986). Measurement of Business Performance in Strategy Research: A Comparison of Approaches. Academy of Management Review, 11(4), 801-814. https://doi.org/10.2307/258398

Wang, Z., \& Wang, N. (2012). Knowledge Sharing, Innovation and Firm Performance. Expert Systems with Applications, 39(10), 8899-8908. https://doi.org/10.1016/j.eswa.2012.02.017

Wu, X., Dou, W., \& Fan, Z., (2009). Shifting from knowledge exploitation to knowledge exploration in new product development: $A$ case study on haier washing machine. International Conference on Information Management, Innovation Management and Industrial Engineering, Xi'an, China. https://doi.org/10.1109/ICIII.2009.584

Xu, J., \& Quaddus, M. (2005).Adoption and Diffusion of Knowledge Management Systems: An Australian Survey. Journal of Management Development, 24(4), 335-361. https://doi.org/10.1108/02621710510591343 


\section{Appendix: Questionnaire items}

Knowledge Management Practices (KMP) (Adapted from CWA 2004; Earl 2003, 2005; OECD, 2005)

Knowledge maintenance and protection: Number of implemented practices from a list of five activities linked to knowledge maintenance and protection

External knowledge capturing: Number of implemented practices from a list of four activities linked to the capture of external knowledge

Knowledge codification: Number of implemented practices from a list of six activities linked to knowledge codification

Knowledge practices focused on the human factor: Number of implemented practices from a list of seven activities linked to practices focused on the human factor

Knowledge Management Performance (KMPerf) (5-point Likert scale) (Powell \& Dent-Micallef, 1997)

kmperf1: Our knowledge management has dramatically increased our organization's productivity

kmperf2: Our knowledge management has improved our competitive position

kmperf3: Our knowledge management has dramatically increased our profitability

kmperf4: Our knowledge management has dramatically increased our revenues

kmperf5: Our knowledge management has dramatically improved our overall performance

Information Technology Infrastructure (IT)(Adapted from Alavi \& Leidner, 2001; Xu \& Quaddus, 2005, Turban et al., 2010)

Communication and collaboration technologies: Number of implemented technologies from a list of nine IT options to support both communication and collaboration in the organization

Information storage and recovery technologies: Number of implemented technologies from a list of ten IT options to support both the storage and recovery of information and knowledge in the organization

Business intelligence applications: Number of implemented technologies from a list of five IT options to support business intelligence initiatives in the organization

Organizational Performance (OP) (5-point Likert scale) (Powell and Dent-Micallef, 1997)

op1: Over the past 4 years, our financial performance has been outstanding

op2: Over the past 4 years, our financial performance has exceeded that of our competitors

op3: Over the past 4 years, our sales growth has been outstanding

op4: Over the past 4 years, we have been more profitable than our competitors

op5: Over the past 4 years, our sales growth has exceeded that of our competitors

Innovation (I) (1= no innovation in processes and products, and 4= innovation in processes and

products (Adapted from Earl, 2005)

Over the past 3 years, what has been the result of your innovation efforts?

Size $(S)$

How many employees has your organization?

Intangible Capital, 2018 (www.intangiblecapital.org)

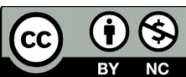

Article's contents are provided on an Attribution-Non Commercial 4.0 Creative commons International License. Readers are allowed to copy, distribute and communicate article's contents, provided the author's and Intangible Capital's names are included. It must not be used for commercial purposes. To see the complete license contents, please visit https://creativecommons.org/licenses/by-nc/4.0/. 